\title{
Pathology and Pathogenesis of SARS-CoV-2 Associated with Fatal Coronavirus Disease, United States
}

Roosecelis B. Martines, ${ }^{1}$ Jana M. Ritter, ${ }^{1}$ Eduard Matkovic, Joy Gary, Brigid C. Bollweg, Hannah Bullock, Cynthia S. Goldsmith, Luciana Silva-Flannery, Josilene N. Seixas, Sarah Reagan-Steiner, Timothy Uyeki, Amy Denison, Julu Bhatnagar, Wun-Ju Shieh, Sherif R. Zaki; COVID-19 Pathology Working Group ${ }^{2}$

An ongoing pandemic of coronavirus disease (COVID-19) is caused by infection with severe acute respiratory syndrome coronavirus 2 (SARS-CoV-2). Characterization of the histopathology and cellular localization of SARS-CoV-2 in the tissues of patients with fatal COVID-19 is critical to further understand its pathogenesis and transmission and for public health prevention measures. We report clinicopathologic, immunohistochemical, and electron microscopic findings in tissues from 8 fatal laboratory-confirmed cases of SARS-CoV-2 infection in the United States. All cases except 1 were in residents of long-term care facilities. In these patients, SARS-CoV-2 infected epithelium of the upper and lower airways with diffuse alveolar damage as the predominant pulmonary pathology. SARS-CoV-2 was detectable by immunohistochemistry and electron microscopy in conducting airways, pneumocytes, alveolar macrophages, and a hilar lymph node but was not identified in other extrapulmonary tissues. Respiratory viral co-infections were identified in 3 cases; 3 cases had evidence of bacterial co-infection.

The ongoing global pandemic of coronavirus dis1 ease (COVID-19), caused by severe acute respiratory syndrome coronavirus 2 (SARS-CoV-2), was identified in Wuhan, Hubei Province, China, and has spread rapidly around the world $(1,2)$. As of May 18, 2020, World Health Organization official data reported 4,628,903 confirmed cases and 312,009 deaths (2). On January 20, 2020, the Centers for Disease Control and Prevention (CDC) confirmed a case in the

Author affiliations: Centers for Disease Control and Prevention, Atlanta, Georgia, USA (R.B. Martines, J.M. Ritter, E. Matkovic,

J. Gary, B.C. Bollweg, C.S. Goldsmith, L. Silva-Flannery,

J.N. Seixas, S. Reagan-Steiner, T. Uyeki, A. Denison,

J. Bhatnagar, W.-J. Shieh, S.R. Zaki); Synergy America Inc.,

Atlanta (H. Bullock).

DOI: https://doi.org/10.3201/eid2609.202095
United States; since then, all 50 US states, District of Columbia, Guam, Puerto Rico, Northern Mariana Islands, and US Virgin Islands have confirmed cases of COVID-19 (2-4).

Coronaviruses are enveloped, positive-stranded RNA viruses that infect many animals; humanadapted viruses likely are introduced through zoonotic transmission from animal reservoirs $(5,6)$. Most known human coronaviruses are associated with mild upper respiratory illness. SARS-CoV-2 belongs to the group of betacoronaviruses that includes severe acute respiratory syndrome coronavirus (SARS-CoV) and Middle East respiratory syndrome coronavirus (MERS-CoV), which can infect the lower respiratory tract and cause a severe and fatal respiratory syndrome in humans (7). SARS-CoV-2 has $\geq 79.6 \%$ similarity in genetic sequence to SARS-CoV (5).

SARS-CoV-2 is highly transmissible among humans; fatality rates for COVID-19 vary and are higher among the elderly and persons with underlying conditions or immunosuppression $(8,9)$. The current knowledge about COVID-19 pathogenesis and pathology in fatalities is based on a small number of described cases and extrapolations from what is known about other similar coronaviruses, such as SARS-CoV and MERSCoV (10-18). Pathologic evaluation and determination of virus distribution and cellular localization within tissues is crucial to elucidating the pathogenesis of these fatal infections and can help guide development of therapeutic and preventive countermeasures. We report on the histopathologic features and detection of virus in tissues by immunohistochemistry (IHC) and electron microscopy (EM) from 8 confirmed fatal cases of COVID-19 in the United States.

\footnotetext{
${ }^{1}$ These authors contributed equally to this article.

${ }^{2}$ Members of the COVID-19 Pathology Working Group: Rhonda Cole, Amanda Lewis, Pamela Fair, Lindsey Estetter.
} 


\section{Materials and Methods}

\section{Study Patients and Data Collection}

As part of the public health response to COVID-19, the CDC Infectious Diseases Pathology Branch (Division of High-Consequence Pathogens and Pathology, National Center for Emerging and Zoonotic Infectious Diseases) was consulted on autopsies of 8 patients with laboratory evidence of SARS-CoV-2 by reverse transcription PCR (RT-PCR) on respiratory swab specimens collected either before or after death. We reviewed available medical records and preliminary autopsy reports for information regarding demographics, symptom history, underlying conditions, infectious disease testing, imaging study findings, treatment and advanced supportive care received, and date of death. This investigation was reviewed in accordance with $\mathrm{CDC}^{\prime}$ s human subjects review procedures and was determined to not meet the definition of research.

\section{Histopathology and Immunohistochemistry}

We performed routine hematoxylin-eosin stains for histopathologic evaluation. We conducted an IHC assay for SARS-CoV-2 using a rabbit polyclonal antibody raised against SARS-CoV nucleocapsid (Novus Biologicals, https://www.novusbio.com) (19) at 1:100 dilution and a Mach 4 Universal AP Polymer Kit (Biocare Medical, https://biocare.net) with Permanent Red Chromogen (Cell Marque/Millipore Sigma, https://www.cellmarque.com). We pretreated the slides with heat-induced epitope retrieval with a citrate-based buffer (Biocare Medical). We ran appropriate negative controls in parallel, using normal rabbit serum in place of the primary antibody. We validated cross reactivity of the anti-SARS-CoV antibody with SARS-CoV-2 by testing controls created from SARS-CoV-2-infected Vero cells embedded with normal human tissues; we used this control as the positive control for subsequent IHC assays. The SARS-CoV nucleocapsid antibody did not cross-react with influenza $\mathrm{A}(\mathrm{H} 1 \mathrm{~N} 1)$ virus, influenza $\mathrm{B}$ virus, respiratory syncytial virus, parainfluenza virus type 3, human coronavirus (HCoV) 229E, or MERS-CoV in PCR-confirmed tissue samples. For cases with bronchopneumonia, we performed IHC testing for bacterial agents using a mouse monoclonal antibody raised against Streptococcus pneumoniae but known to also detect other Streptococcus spp. and a rabbit polyclonal anti-Klebsiella pneumoniae antibody (both from Thermo Fisher, https://www.thermofisher.com) known to also detect other gram-negative bacteria (Escherichia coli, Haemophilus influenzae, and Pseudomonas spp.).
For double-stained assays, we used Envision G/2 Double Stain System, Rabbit/Mouse (DAB Permanent Red) from Agilent Technologies (https:/ / www. agilent.com). We used antibodies against CD163 (Leica Biosystems, https://www.leicabiosystems.com) or surfactant apoprotein A (Dako, https://www. agilent.com), followed by the anti-SARS-CoV nucleocapsid antibody (Novus Biologicals). We performed all assays according to the manufacturer's guidelines. We used SARS-CoV-2-infected Vero cells as a positive control and used non-COVID-19 cases and normal rabbit serum in place of primary antibody as negative controls.

\section{Electron Microscopy}

We obtained upper airway and lung tissue specimens from formalin-fixed samples, cut them into cubes, rinsed them with $0.1 \mathrm{mmol} / \mathrm{L}$ phosphate buffer, postfixed them with $2.5 \%$ glutaraldehyde, and rinsed them in phosphate buffer. In addition, we removed tissue samples from areas corresponding to positive SARSCoV-2 immunostaining from paraffin blocks with a 2-mm punch or from $4-\mu \mathrm{m}$ sections on glass slides; we deparaffinized the samples in xylene and rehydrated. We processed tissues for transmission EM as described previously (20). We immersed the sections embedded in epoxy resin in boiling water, removed them from the slides with a razor blade, and cut out the areas of interest and glued them onto a blank EM block. We stained EM sections with uranyl acetate and lead citrate and examined them on a Thermo Fisher/FEI Tecnai Spirit or Tecnai BioTwin electron microscope.

\section{RT-PCR}

We extracted nucleic acids from formalin-fixed paraffin-embedded (FFPE) tissues and assessed them by a conventional RT-PCR specifically targeting the nucleocapsid gene of SARS-CoV-2 (J. Bhatnagar, unpub. data) and real-time RT-PCR/PCR targeting other respiratory pathogens, including influenza viruses, respiratory syncytial virus, human parainfluenza viruses, and Streptococcus pneumoniae, as described previously $(21,22)$. The SARS-CoV-2 nucleocapsid assay detects SARS-CoV-2 and SARS-CoV but does not amplify MERS-CoV and other common human coronaviruses, including alphacoronavirus (HCoV-NL63) and betacoronavirus (HCoV-HKU1).

\section{Results}

\section{Clinical Data}

Of the 8 case-patients, 7 were residents of a longterm care facility (LTCF) in Washington state (Table 
Table 2. Histopathologic features and severe acute respiratory syndrome coronavirus 2 detection in respiratory tissues from 8 coronavirus disease fatalities*

\begin{tabular}{|c|c|c|c|c|c|c|c|c|}
\hline Patient no. & 1 & 2 & 3 & 4 & 5 & 6 & 7 & 8 \\
\hline $\begin{array}{l}\text { Minimum symptom } \\
\text { duration, } d\end{array}$ & 13 & 10 & 5 & 13 & 16 & 11 & 12 & 7 \\
\hline Tracheobronchitis & ++ & + & + & + & + & + & ++ & + \\
\hline DAD, acute & + & + & ++ & ++ & - & - & - & +++ \\
\hline DAD, organizing & +++ & + & ++ & ++ & + & + & - & +++ \\
\hline Squamous metaplasia & + & - & - & + & - & - & - & + \\
\hline Atypical pneumocytes & +++ & - & - & + & - & - & - & + \\
\hline Interstitial pneumonitis & + & - & - & + & - & ++ & - & + \\
\hline Bronchopneumonia & - & - & + & + & + & - & +++ & - \\
\hline $\begin{array}{l}\text { Intravascular } \\
\text { leukocytosis }\end{array}$ & - & - & + & + & + & - & - & - \\
\hline Anthracosis & + & + & + & ++ & ++ & ++ & + & ++ \\
\hline Other lung pathology & - & HLM & $\begin{array}{c}\text { Hemorrhage, } \\
\text { emphysema, } \\
\text { MA }\end{array}$ & HLM, MA & HLM, MA & $\begin{array}{c}\text { Hemorrhage, } \\
\text { corpora } \\
\text { amylacea }\end{array}$ & $\begin{array}{c}\text { Hemorrhage, } \\
\text { HLM, } \\
\text { microthrombi }\end{array}$ & $\begin{array}{l}\text { Hemorrhage, } \\
\text { emphysema }\end{array}$ \\
\hline $\begin{array}{l}\text { SARS-CoV-2 IHC, } \\
\text { upper airway }\end{array}$ & - & - & - & - & ** & ** & * & * \\
\hline SARS-CoV-2 IHC, lung & - & + & +++ & +++ & +++ & + & ++ & ++ \\
\hline $\begin{array}{l}\text { Electron microscopy, } \\
\text { viral particles }\end{array}$ & NA & NA & + & + & + & + & NA & NA \\
\hline Other agents detected & $\begin{array}{c}\text { Influenza } \\
\text { B }\end{array}$ & - & - & $\begin{array}{c}\text { Streptococcus } \\
\text { spp. }\end{array}$ & $\mathrm{PI}-3$ & $\begin{array}{c}\text { Streptococcus } \\
\text { spp. }\end{array}$ & $\mathrm{PI}-3$ & $\begin{array}{c}\text { Streptococcus } \\
\text { spp. }\end{array}$ \\
\hline
\end{tabular}

from all 8 case-patients were positive by SARS-CoV-2 RT-PCR. Double staining with surfactant showed colocalization of SARS-CoV-2 antigen with type II pneumocytes (Figure 3, panel D); double staining with CD-163 showed viral antigen colocalization with macrophages (Figure 3, panel E). We also found viral immunostaining in scattered macrophages in the hilar lymph node from 1 severely immunosuppressed patient with a history of solid-organ transplant (Figure 3, panel G). We did not detect SARS-CoV-2 by IHC in heart, liver, kidney, spleen, or intestine from any patient.

Six $(75 \%)$ of 8 case-patients had either viral or bacterial co-infections, but not both, identified by IHC, PCR, or both in addition to SARS-CoV-2. Respiratory viral PCR testing detected parainfluenza virus type 3 coinfection in upper airway and lung tissue in $2 / 8$ $(25 \%)$ case-patients and influenza B virus coinfection in upper airway in 1 case-patient. Three $(75 \%)$ of the 4 case-patients with SARS-CoV-2 and bronchopneumonia had immunostaining for Streptococcus spp. Two of these patients had nonpneumococcal Streptococcus spp. confirmed by PCR testing.

EM examination of respiratory tissues showed virions with prominent surface projections (spikes) characteristic of the family Coronaviridae. In the lung, extracellular virions free in the alveolar space were, on average, $105 \mathrm{~nm}$ in diameter, including surface projections (Figure 4, panel A). In upper airways, virions were seen extracellularly among the cilia and within the cytoplasm of respiratory epithelial cells
(Figure 4, panel B; Figure 5). Intracellular virions in type II pneumocytes (Figure 4, panels C, D) and in cytoplasmic vesicles or phagosomes of alveolar macrophages (Figure 4, panel E) were, on average, $75 \mathrm{~nm}$ in diameter and lacked prominent spikes. Viral particles were also found associated with fibrin or hyaline membranes within alveolar spaces (Figure 4, panel F).

\section{Discussion}

The clinical distinction between SARS-CoV-2 and other respiratory viral infections is difficult because there are overlapping clinical features characterized by febrile illness with cough that lasts for several days before progressing to acute pneumonia. In addition, persons with SARS-CoV-2 and other respiratory viral infections may have atypical or minimal symptoms $(25-27)$. Besides respiratory failure, particularly in patients with severe disease, fatigue, myalgia or arthralgia, chills, hepatic and renal dysfunction, lymphocytopenia, leukopenia, thrombocytopenia, and elevated inflammatory biomarkers have been described $(5,28,29)$.

Histopathologic lesions attributed directly to the virus in these cases were limited to respiratory tissues; the predominant finding was DAD, with various levels of progression and severity. We saw no clear correlation of the pathologic phase of DAD to known symptom duration, which could be the result of underrecognition of early symptoms in elderly residents of LTCFs and underestimation of illness duration. Together, the histopathologic, IHC, and 


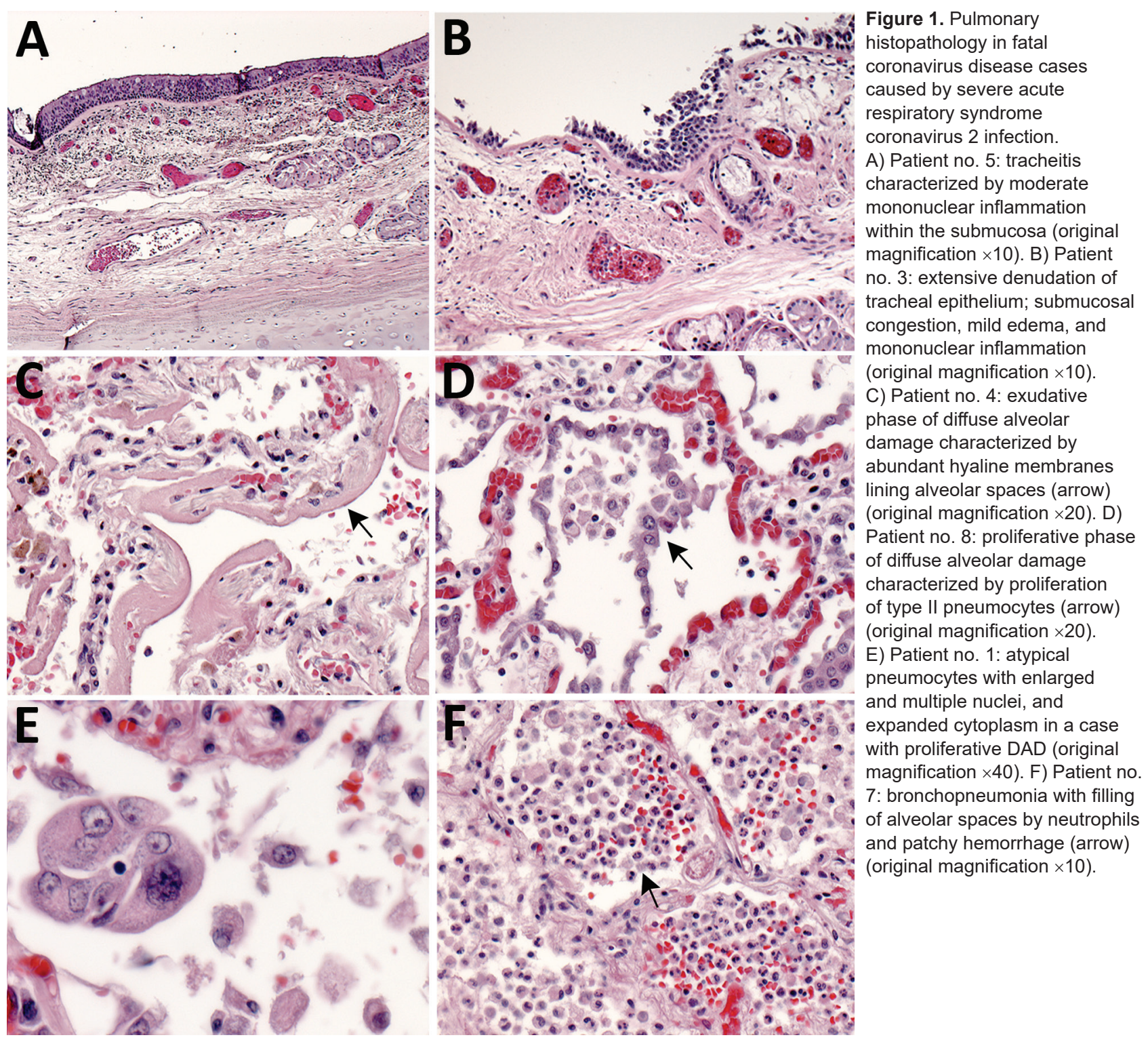

EM findings in this report provide insight into SARSCoV-2 pathogenesis. IHC testing, including double staining with surfactant, and EM confirmed viral tropism for pulmonary II pneumocytes. The ultrastructural observations are consistent with previous reports of SARS-CoV infection, with the exception that neither double-membrane vesicles nor nucleocapsid inclusions were detected $(15,20)$. Viral antigen was also seen in respiratory epithelium of conducting airways (trachea, bronchi, and bronchioles) and occasionally in alveolar macrophages; infection of these cell types may be key in viral replication and trafficking. The respiratory epithelium is one of the first cell types encountered by inhaled virus; SARS-CoV-2 antigens were detected by IHC in ciliated epithelial cells from $50 \%$ of these case-patients and up to 16 days after known symptom onset. Ultrastructural analysis showed numerous extracellular viral particles along the ciliated surface and within ciliated columnar epithelial cells. These findings corroborate reports of high viral loads in the upper respiratory tract and support the potential for persons infected with SARSCoV-2 to readily transmit the virus, with prolonged and continued viral shedding in severe cases $(30,31)$.

Overall pathologic features in these 8 COVID-19 deaths were similar to those seen in SARS-CoV and MERS-CoV infections, and in available COVID-19 reports $(10-15,18,20,32)$. However, the amount of viral antigen detected by IHC in lung tissue from these cases is more than what we have seen in SARS and MERS $(16,18)$ cases submitted to our laboratory, and its extensive detection in epithelial cells of 
the upper respiratory tract is unique among these highly pathogenic coronaviruses (33). In addition to direct viral effects on tissues, the immune response to viral infection likely plays a major role in determining clinical outcome, and acute decline in COVID-19 patients has been linked to an immune-mediated cytokine storm (34). Preliminary evaluation of immune cell populations in the respiratory tissues from these 8 cases revealed abundant $\mathrm{T}$ lymphocytes in the upper airways and lung parenchyma, with B lymphocytes in smaller numbers and predominating in areas of lymphoid aggregates (data not shown). Further investigation into the roles of these cell populations in COVID-19 is needed. In 6 of the 8 case-patients, sinus histiocytosis and hemophagocytosis were seen in hilar lymph nodes. However, SARS-CoV-2 anti- gens were detected by IHC in hilar lymph node macrophages from only 1 immunosuppressed patient. Lymph nodes are key sites for immune recognition and elimination of respiratory pathogens. Elucidating the immune response to, and the effects of immunosuppression on, SARS-CoV-2 infection is therefore of fundamental importance.

SARS-CoV-2 uses the angiotensin-converting enzyme 2 (ACE2) receptor to facilitate viral entry into target cells. ACE2 is expressed in multiple tissues throughout the body, including type II pneumocytes, myocardial cells, cholangiocytes, enterocytes, and oral mucosal epithelium $(5,35,36)$. However, among these patients, SARS-CoV-2 antigens were not detected in extrapulmonary tissues besides hilar lymph node, and pathologic findings in other tissues were

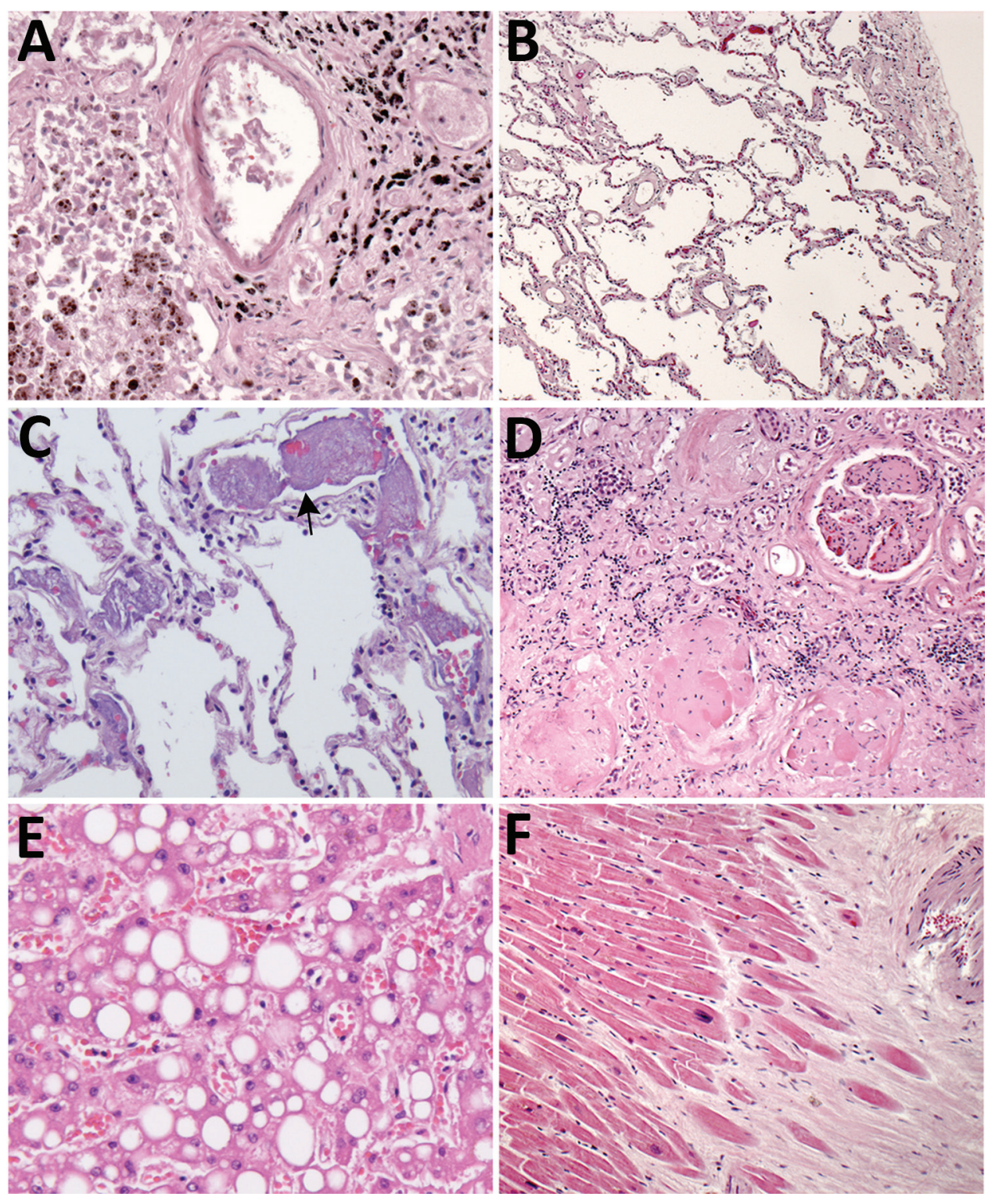

Figure 2. Histopathologic findings associated with underlying conditions in fatal coronavirus disease. A) Patient no. 2: lung, hemosiderin-laden macrophages (brown pigment, bottom left), and anthracosis (black pigment, top right) in a patient with congestive heart failure (original magnification $\times 20$ ). B) Patient no. 3: lung, emphysema in a patient with chronic obstructive pulmonary disease (original magnification $\times 5$ ). C) Patient no. 7: lung, pulmonary microthrombosis (arrow) (original magnification $\times 20$ ). D) Patient no. 2: kidney, extensive glomerulosclerosis in a patient with renal disease (original magnification $\times 10$ ). E) Patient no. 3: liver, steatosis in a patient with morbid obesity (original magnification $\times 20$ ). F) Patient no. 2: heart, myocardial fibrosis and mild cardiomyocyte hypertrophy in a patient with cardiomegaly (original magnification $\times 5$ ). 


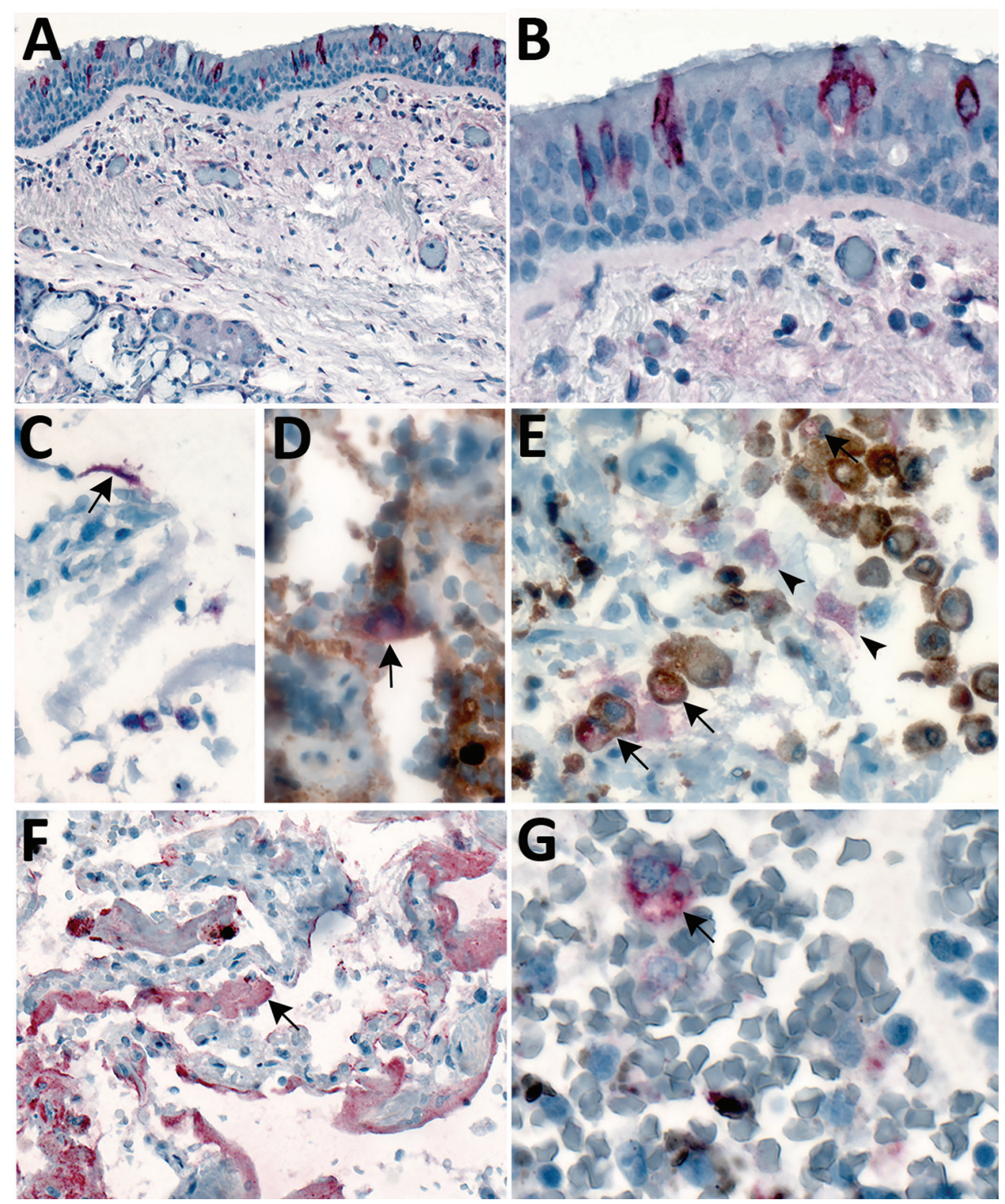

Figure 3. Immunostaining of severe acute respiratory syndrome coronavirus 2 in pulmonary tissues from fatal coronavirus disease cases. A) Patient no. 5: scattered immunostaining of tracheal epithelial cells (original magnification $\times 40$ ). B) Patient no. 5: higher magnification shows immunostaining of ciliated cells (original magnification $\times 63$ ). C) Patient no. 8: immunostaining of desquamated type I pneumocyte in an alveolar lumen (original magnification $\times 63$ ). D) Patient no. 4: colocalization of SARSCoV-2 viral antigen (red) with type II pneumocyte stained by surfactant (brown; arrow) (original magnification $\times 63$ ). E) Patient no. 4: colocalization of SARS-CoV-2 viral antigen (red) with macrophages stained by CD163 (brown; arrows); virus immunostaining within type II pneumocytes is also seen (arrowheads) (original magnification $\times 40$ ). F) Patient no. 4: extensive immunostaining of hyaline membranes in a region of exudative DAD (original magnification $\times 20$ ). G) Patient no. 3: scattered immunostaining within macrophage in hilar lymph node; anthracosis is also present (original magnification $\times 63$ ).

attributable to other underlying concurrent conditions. Some of the underlying conditions in these case-patients (e.g., hypertension, COPD) are associated with upregulation of ACE2 receptors; possible correlation of these conditions with COVID-19 severity warrants further exploration $(5,28,37)$. COVID-19 cardiomyopathy and acute cardiac death during clinical resolution of pulmonary disease have been described $(24,38)$. However, we did not observe any evidence of myocarditis or myocardial necrosis in the tissues of the 8 case-patients we examined. Reports have been made of coagulation abnormalities and pulmonary vascular perfusion issues without DAD in some COVID-19 patients $(39,40)$, and we saw microthrombi in the lung from 1 case-patient who lacked DAD but had severe bacterial bronchopneumonia. These various and potentially severe cardiovascular complications of COVID-19 warrant further investigation into the specific mechanisms of SARS-CoV-2-induced cardiovascular injury, homeostatic derangement, or both.

Clinical studies have reported elevated liver enzymes in patients with COVID-19 $(28,29)$. The lack of viral detection by IHC in the liver in this investigation suggests that for these case-patients, abnormal biomarkers of hepatic injury may not be the result of direct viral infection of hepatocytes. Gastrointestinal symptoms are not typically a prominent feature of COVID-19 but have been reported, and SARS-CoV-2 has been detected in fecal samples (41-43). However, no histopathologic findings or SARS-CoV-2 antigens were detected in gastrointestinal tissues, and diarrhea was reported for only 1 of these case-patients. 
We identified viral co-infections in upper respiratory tract tissues from 3 case-patients, including 2 with parainfluenza virus 3 and 1 with influenza B virus, but the contribution of these co-infections to pulmonary disease and fatal outcomes is unknown. Although we identified streptococcal lower respiratory infections in 3 case-patients, none were caused by Streptococcus pneumoniae, and there was no strict correlation of these infections with mechanical ventilation among these case-patients. Because 7 of 8 case-patients discussed in this report were residents of a LTCF, their exposures and risks for viral and bacterial co-infections may be different from those for other patients. Few community-acquired bacterial
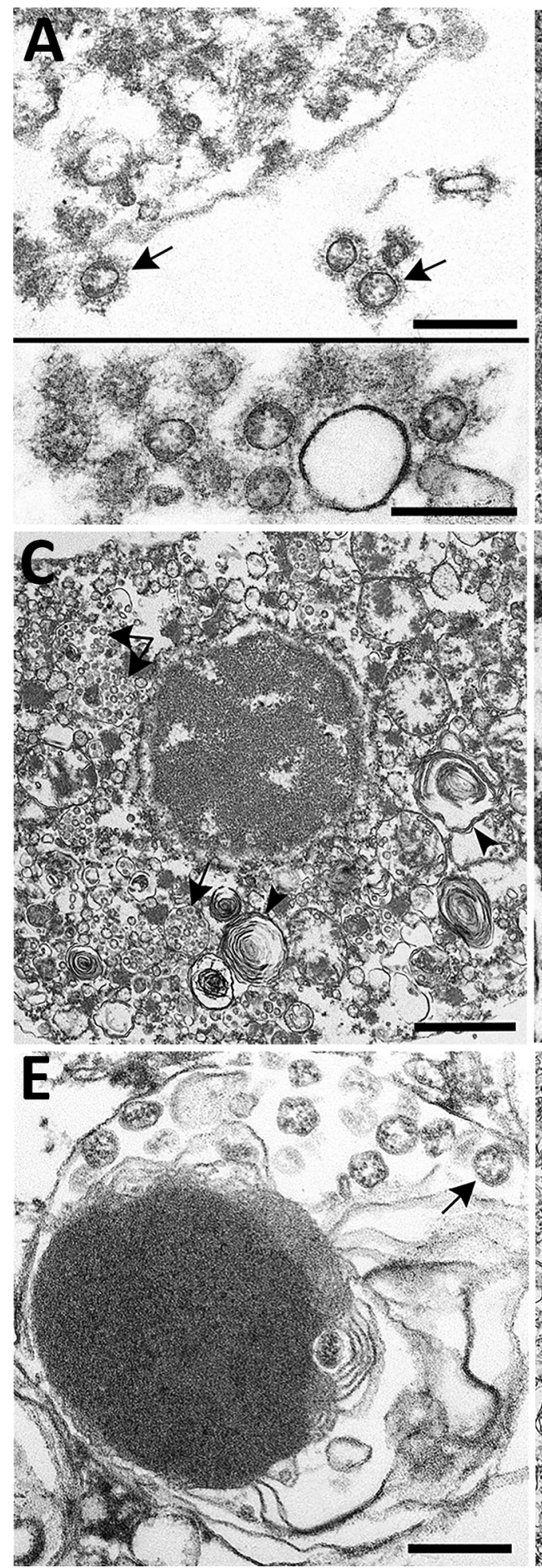
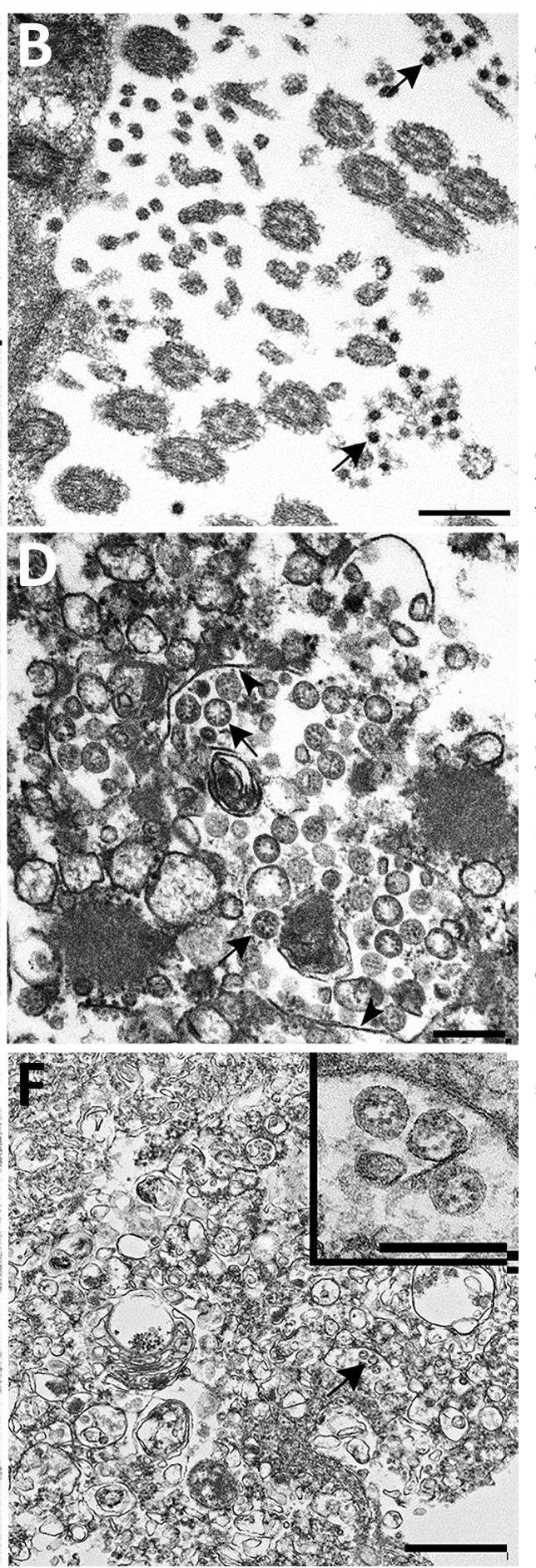

Figure 4. Ultrastructural features of severe acute respiratory syndrome coronavirus 2 lung infection in fatal coronavirus disease. A) Top: alveolar space containing extracellular virions (arrows) with prominent surface projections. Bottom: cluster of virions in the alveolar space.

Scale bars indicate $200 \mathrm{~nm}$. B) Extracellular virions (arrow) associated with ciliated cells of the upper airway. Scale bar indicates $200 \mathrm{~nm}$. C) Membranebound vacuoles (arrows) containing viral particles within the cytoplasm of an infected type II pneumocyte; surfactant (lamellated material) indicted by arrowheads. Scale bar indicates $1 \mu \mathrm{m}$. D) Membranebound vacuole (double-headed arrow in panel C) containing virus particles (arrows) with the characteristic black dots that are cross-sections through the viral nucleocapsid. Arrowheads indicate vacuolar membrane. Scale bar indicates $200 \mathrm{~nm}$. E) Viral particles (arrow) within a phagosome of an alveolar macrophage. Scale bar: $200 \mathrm{~nm}$. F) Viral particles within a portion of a hyaline membrane. Scale bar indicates $800 \mathrm{~nm}$. Inset: Higher magnification of virus particles indicated by arrow; scale bar indicates $200 \mathrm{~nm}$. 


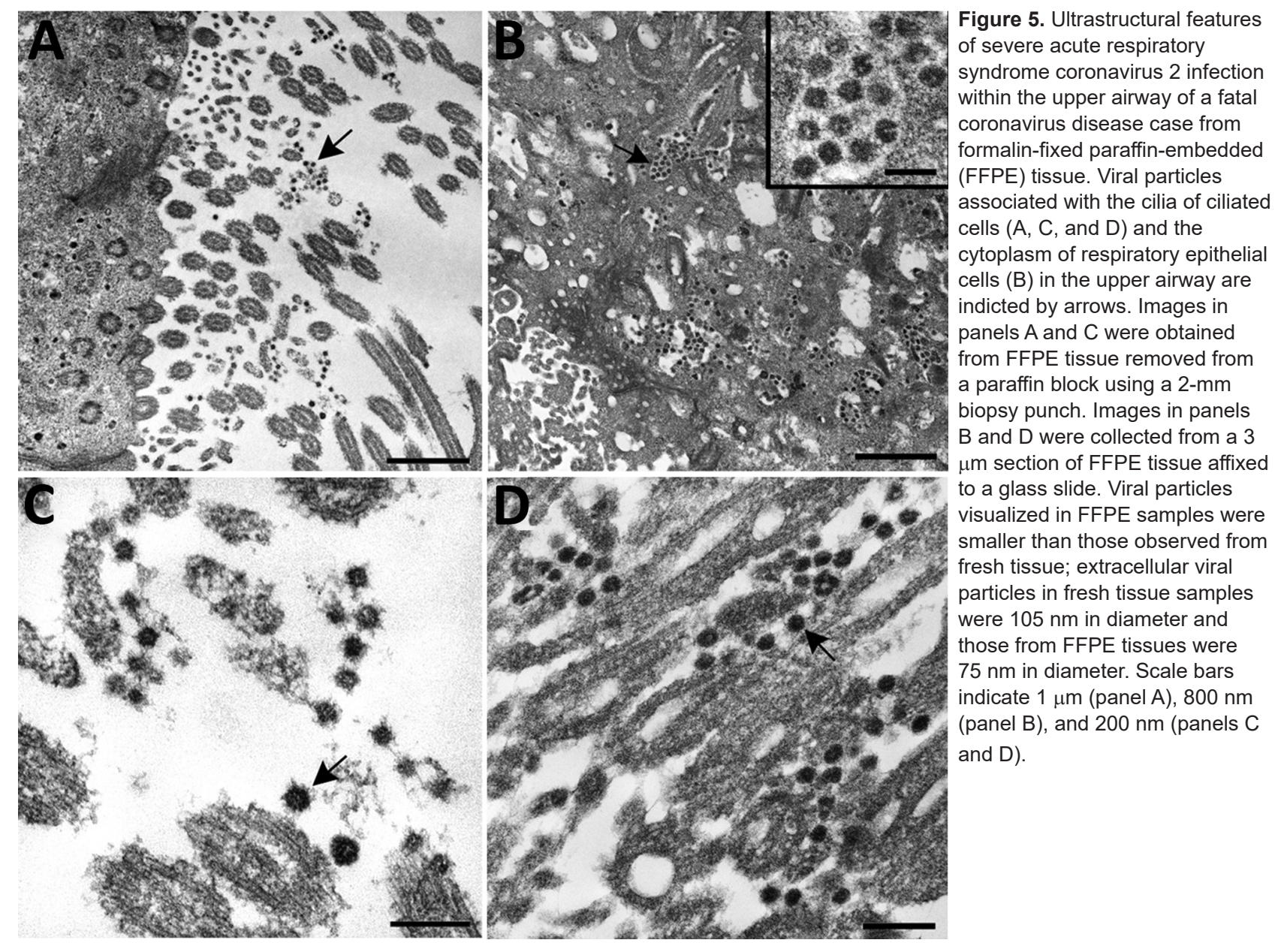

infections have been reported in critically ill patients with COVID-19, but co-infections are not frequently reported with SARS and MERS $(17,32,44)$. Co-infections may play a key role in increasing susceptibility to, and illness from, SARS-CoV-2 infection in a LTCF setting. Further investigation into this association, and characterization of the etiologic agents most commonly involved, is warranted and may contribute to improved overall management of COVID-19 disease.

This report describes the specific cellular and extracellular localization of SARS-CoV-2 in respiratory tissues, without any IHC evidence of the virus in other tissues. Although detection of SARS-CoV-2 RNA in blood or serum has been reported $(34,41)$, we did not find evidence of systemic virus dissemination in these case-patients. Our findings highlight the importance of underlying conditions and pulmonary co-infections in COVID-19; these factors may potentially delay or confound diagnosis and contribute to adverse outcomes.

A limitation of this study is that 7 of 8 cases were from a single skilled nursing facility; findings may therefore not be representative of community-acquired SARS-CoV-2 infections. However, nosocomial transmission of viruses often parallels community outbreaks, and understanding disease transmission in healthcare settings is crucial $(25,45)$. None of these case-patients had diagnoses of acute cardiac injury, myocarditis, or cardiomyopathy, so understanding the pathogenesis of cardiac injury with SARS-CoV-2 infection requires additional investigations in fatal cases with evidence of cardiac injury.

No clinical or histopathologic features are specific to SARS-CoV-2 infection. Demonstrating SARSCoV-2 directly in lung tissue, when taken in context with any other pathology present, is critical to assessing its contribution to mortality. Herein, we establish the utility of IHC as a diagnostic modality for SARS-CoV-2 in FFPE tissues by localizing viral antigens in respiratory tissues from RT-PCR confirmed cases. This diagnostic method is particularly valuable for FFPE specimens from cases in which antemortem or postmortem respiratory swab testing for SARS-CoV-2 was not performed. We also 
demonstrate virus identification in tissues by EM using various tissue sources (formalin-fixed wet tissue, FFPE blocks, and stained slides). Identification of SARS-CoV-2 cellular tropisms in the respiratory tract represents a crucial step forward in understanding the pathogenesis of SARS-CoV-2 infection and provides some insights relevant to the development of targeted therapeutic and preventive measures to combat COVID-19.

\section{Acknowledgments}

We thank Mitesh Patel and Monica Peabody for accessioning the cases, Natalie Thornburg and Azaibi Tamin for providing SARS-CoV-2 Vero cells culture, and Dominique Rollin for the preparation of SARS-CoV-2 culture control blocks. We also thank Nicole Yarid and Micheline Lublin for specimen collection; Agam Rao; Kaitlyn Sykes and Jessica Ferro for facilitating data collection and coordination efforts; and staff from the King County Medical Examiner's Office for their commitment in the context of this pandemic disease.

\section{About the Authors}

Dr. Martines is a pathologist with the Division of High-Consequence Pathogens and Pathology, National Center for Emerging and Zoonotic Infectious Diseases, CDC, Atlanta, Georgia, USA. Her primary research interest is in the pathology and pathogenesis of emerging infectious diseases, with particular interest in viral hemorrhagic fevers. Dr. Ritter is a pathologist with the Division of High-Consequence Pathogens and Pathology, National Center for Emerging and Zoonotic Infectious Diseases, CDC, Atlanta. Her primary research interest is the development of animal models for zoonotic and human infectious diseases.

\section{References}

1. Zhu N, Zhang D, Wang W, Li X, Yang B, Song J, et al.; China Novel Coronavirus Investigating and Research Team. A novel coronavirus from patients with pneumonia in China, 2019. N Engl J Med. 2020;382:727-33. https:/ / doi.org/ 10.1056/NEJMoa2001017

2. World Health Organization. Coronavirus disease (COVID-19) pandemic. 2020 May 4 [cited 2020 May 5]. https://www.who.int/emergencies/diseases/novelcoronavirus-2019

3. Holshue ML, DeBolt C, Lindquist S, Lofy KH, Wiesman J, Bruce H, et al.; Washington State 2019-nCoV Case Investigation Team. First case of 2019 novel coronavirus in the United States. N Engl J Med. 2020;382:929-36. https://doi.org/10.1056/NEJMoa2001191

4. Harcourt J, Tamin A, Lu X, Kamili S, Sakthivel SK, Murray J, et al. Severe acute respiratory syndrome coronavirus 2 from patient with 2019 novel coronavirus disease, United States. Emerg Infect Dis. 2020;26:26. https:/ / doi.org/10.3201/ eid2606.200516
5. Zhou P, Yang XL, Wang XG, Hu B, Zhang L, Zhang W, et al. A pneumonia outbreak associated with a new coronavirus of probable bat origin. Nature. 2020;579:270-3. https:/ / doi.org/10.1038/s41586-020-2012-7

6. Andersen KG, Rambaut A, Lipkin WI, Holmes EC, Garry RF. The proximal origin of SARS-CoV-2. Nat Med. 2020;26:450-2. https:/ / doi.org/10.1038/s41591-020-0820-9

7. Chen Y, Liu Q, Guo D. Emerging coronaviruses: genome structure, replication, and pathogenesis. J Med Virol. 2020;92:418-23. https://doi.org/10.1002/jmv.25681

8. Bialek S, Boundy E, Bowen V, Chow N, Cohn A, Dowling N, et al.; CDC COVID-19 Response Team. Severe outcomes among patients with coronavirus disease 2019 (COVID-19) United States, February 12-March 16, 2020. MMWR Morb Mortal Wkly Rep. 2020;69:343-6. https:/ / doi.org/10.15585/ mmwr.mm6912e2

9. Wu Z, McGoogan JM. Characteristics of and important lessons from the coronavirus disease 2019 (COVID-19) outbreak in China: summary of a report of 72,314 cases from the Chinese Center for Disease Control and Prevention. JAMA. 2020;323:1239-42. https:// doi.org/ 10.1001/jama.2020.2648

10. Xu Z, Shi L, Wang Y, Zhang J, Huang L, Zhang C, et al. Pathological findings of COVID-19 associated with acute respiratory distress syndrome. Lancet Respir Med. 2020; 8:420-2. https:// doi.org/10.1016/S2213-2600(20)30076-X

11. Tian S, Hu W, Niu L, Liu H, Xu H, Xiao SY. Pulmonary pathology of early-phase 2019 novel coronavirus (COVID-19) pneumonia in two patients with lung cancer. J Thorac Oncol. 2020;15:700-4. https:/ / doi.org/10.1016/ j.jtho.2020.02.010

12. Barton LM, Duval EJ, Stroberg E, Ghosh S, Mukhopadhyay S. COVID-19 autopsies, Oklahoma, USA. Am J Clin Pathol. 2020;153:725-33. https:// doi.org/10.1093/ajcp/aqaa062

13. Menter T, Haslbauer JD, Nienhold R, Savic S, Hopfer H, Deigendesch N, et al. Post-mortem examination of COVID19 patients reveals diffuse alveolar damage with severe capillary congestion and variegated findings of lungs and other organs suggesting vascular dysfunction. Histopathology. 2020 May 4 [Epub ahead of print]. https://doi.org/10.1111/his.14134

14. Wichmann D, Sperhake JP, Lütgehetmann M, Steurer S, Edler C, Heinemann A, et al. Autopsy findings and venous thromboembolism in patients with COVID-19: a prospective cohort study. Ann Intern Med. 2020 May 6 [Epub ahead of print]. https:/ / doi.org/10.7326/M20-2003

15. Ksiazek TG, Erdman D, Goldsmith CS, Zaki SR, Peret T, Emery S, et al.; SARS Working Group. A novel coronavirus associated with severe acute respiratory syndrome. N Engl J Med. 2003;348:1953-66. https:/ / doi.org/10.1056/ NEJMoa030781

16. Shieh WJ, Hsiao CH, Paddock CD, Guarner J, Goldsmith CS, Tatti K, et al. Immunohistochemical, in situ hybridization, and ultrastructural localization of SARS-associated coronavirus in lung of a fatal case of severe acute respiratory syndrome in Taiwan. Hum Pathol. 2005;36:303-9. https:// doi.org/10.1016/j.humpath.2004.11.006

17. Gu J, Korteweg C. Pathology and pathogenesis of severe acute respiratory syndrome. Am J Pathol. 2007;170:1136-47. https:/ / doi.org/10.2353/ajpath.2007.061088

18. Ng DL, Al Hosani F, Keating MK, Gerber SI, Jones TL, Metcalfe MG, et al. Clinicopathologic, immunohistochemical, and ultrastructural findings of a fatal case of Middle East respiratory syndrome coronavirus infection in the United Arab Emirates, April 2014. Am J Pathol. 2016;186:652-8. https://doi.org/10.1016/j.ajpath.2015.10.024 
19. Tseng CT, Huang C, Newman P, Wang N, Narayanan K, Watts DM, et al. Severe acute respiratory syndrome coronavirus infection of mice transgenic for the human angiotensin-converting enzyme 2 virus receptor. J Virol. 2007;81:1162-73. https:/ / doi.org/10.1128/JVI.01702-06

20. Goldsmith CS, Tatti KM, Ksiazek TG, Rollin PE, Comer JA, Lee WW, et al. Ultrastructural characterization of SARS coronavirus. Emerg Infect Dis. 2004;10:320-6. https://doi.org/10.3201/eid1002.030913

21. Shieh WJ, Blau DM, Denison AM, Deleon-Carnes M, Adem P, Bhatnagar J, et al. 2009 Pandemic influenza A (H1N1): pathology and pathogenesis of 100 fatal cases in the United States. Am J Pathol. 2010;177:166-75. https://doi.org/10.2353/ajpath.2010.100115

22. Trzciński K, Bogaert D, Wyllie A, Chu ML, van der Ende A, Bruin JP, et al. Superiority of trans-oral over trans-nasal sampling in detecting Streptococcus pneumoniae colonization in adults. PLoS One. 2013;8:e60520. https://doi.org/10.1371/ journal.pone.0060520

23. McMichael TM, Clark S, Pogosjans S, Kay M, Lewis J, Baer A, et al.; Public Health - Seattle and King County, EvergreenHealth, and CDC COVID-19 Investigation Team. COVID-19 in a long-term care facility - King County, Washington, February 27-March 9, 2020. MMWR Morb Mortal Wkly Rep. 2020;69:339-42. https:/ / doi.org/10.15585/mmwr.mm6912e1

24. Arentz M, Yim E, Klaff L, Lokhandwala S, Riedo FX, Chong M, et al. Characteristics and outcomes of 21 critically ill patients with COVID-19 in Washington state. JAMA. 2020;141:428.

25. Kimball A, Hatfield KM, Arons M, James A, Taylor J, Spicer K, et al.; Public Health - Seattle and King County; CDC COVID-19 Investigation Team. Asymptomatic and presymptomatic SARS-CoV-2 infections in residents of a long-term care skilled nursing facility - King County, Washington, March 2020. MMWR Morb Mortal Wkly Rep. 2020;69:377-81. https:/ / doi.org/10.15585/mmwr.mm6913e1

26. Arons MM, Hatfield KM, Reddy SC, Kimball A, James A, Jacobs JR, et al. Presymptomatic SARS-CoV-2 infections and transmission in a skilled nursing facility. N Engl J Med. 2020 Apr 24 [Epub ahead of print]. https:/ / doi.org/10.1056/ NEJMoa2008457

27. Luo Y, Trevathan E, Qian Z, Li Y, Li J, Xiao W, et al. Asymptomatic SARS-CoV-2 infection in household contacts of a healthcare provider, Wuhan, China. Emerg Infect Dis. 2020 Apr 24 [Epub ahead of print]. https:// doi.org/10.3201/ eid2608.201016

28. Guan WJ, Ni ZY, Hu Y, Liang WH, Ou CQ, He JX, et al.; China Medical Treatment Expert Group for Covid-19. Clinical characteristics of coronavirus disease 2019 in China. N Engl J Med. 2020;382:1708-20. https:/ / doi.org/10.1056/ NEJMoa2002032

29. Zhang C, Shi L, Wang FS. Liver injury in COVID-19: management and challenges. Lancet Gastroenterol Hepatol. 2020;5:428-30. https://doi.org/10.1016/S2468-1253 (20)30057-1

30. Zhou F, Yu T, Du R, Fan G, Liu Y, Liu Z, et al. Clinical course and risk factors for mortality of adult inpatients with COVID-19 in Wuhan, China: a retrospective cohort study. Lancet. 2020;395:1054-62. https:/ / doi.org/10.1016/ S0140-6736(20)30566-3

31. Zou L, Ruan F, Huang M, Liang L, Huang H, Hong Z, et al. SARS-CoV-2 viral load in upper respiratory specimens of infected patients. N Engl J Med. 2020;382:1177-9. https://doi.org/10.1056/NEJMc2001737
32. Franks TJ, Chong PY, Chui P, Galvin JR, Lourens RM, Reid AH, et al. Lung pathology of severe acute respiratory syndrome (SARS): a study of 8 autopsy cases from Singapore. [Erratum in: Hum Pathol. 2004;35:138.] Hum Pathol. 2003;34:743-8. https://doi.org/10.1016/S0046-8177(03)00367-8

33. Zaki SR, Paddock CD. Viral infections of the lung. In: Tomashefski JF, Cagle PT, Farver CF, Fraire AE, editors. Dail and Hammar's pulmonary pathology. New York: Springer; 2008. p. 426-75.

34. Huang C, Wang Y, Li X, Ren L, Zhao J, Hu Y, et al. Clinical features of patients infected with 2019 novel coronavirus in Wuhan, China. Lancet. 2020;395:497-506. https:/ / doi.org/ 10.1016/S0140-6736(20)30183-5

35. Wrapp D, Wang N, Corbett KS, Goldsmith JA, Hsieh C-L, Abiona O, et al. Cryo-EM structure of 2019-nCoV-2 spike in the prefusion conformation. Science. 2020;367:1260-3. https:// doi.org/10.1126/science.abb2507

36. Xu H, Zhong L, Deng J, Peng J, Dan H, Zeng X, et al. High expression of ACE2 receptor of 2019-nCoV on the epithelial cells of oral mucosa. Int J Oral Sci. 2020;12:8. https://doi.org/10.1038/s41368-020-0074-x

37. Wang Y, Wang Y, Chen Y, Qin Q. Unique epidemiological and clinical features of the emerging 2019 novel coronavirus pneumonia (COVID-19) implicate special control measures. J Med Virol. 2020;92:568-76. https:/ / doi.org/10.1002/ jmv.25748

38. Zheng YY, Ma YT, Zhang JY, Xie X. COVID-19 and the cardiovascular system. Nat Rev Cardiol. 2020;17:259-60. https://doi.org/10.1038/s41569-020-0360-5

39. Terpos E, Ntanasis-Stathopoulos I, Elalamy I, Kastritis E, Sergentanis TN, Politou M, et al. Hematological findings and complications of COVID-19. Am J Hematol. 2020; Apr 13 [Epub ahead of print]. https:/ / doi.org/10.1002/ajh.25829

40. Tan CW, Low JGH, Wong WH, Chua YY, Goh SL, Ng HJ. Critically ill COVID-19 infected patients exhibit increased clot waveform analysis parameters consistent with hypercoagulability. Am J Hematol. 2020 Apr 8 [Epub ahead of print]. https://doi.org/10.1002/ajh.25822

41. Wang W, Xu Y, Gao R, Lu R, Han K, Wu G, et al. Detection of SARS-CoV-2 in different types of clinical specimens. JAMA. 2020 Mar 11 [Epub ahead of print]. http://dx.doi.org/10.1001/jama.2020.3786

42. Xiao F, Tang M, Zheng X, Liu Y, Li X, Shan H. Evidence for gastrointestinal infection of SARS-CoV-2. Gastroenterology. 2020 Mar 3 [Epub ahead of print]. https:/ / doi.org/10.1053/ j.gastro.2020.02.055

43. Bhatraju PK, Ghassemieh BJ, Nichols M, Kim R, Jerome KR, Nalla AK, et al. Covid-19 in critically ill patients in the Seattle region - case series. N Engl J Med. 2020 Mar 30 [Epub ahead of print]. https://doi.org/10.1056/NEJMoa2004500

44. Zumla A, Hui DS, Perlman S. Middle East respiratory syndrome. Lancet. 2015;386:995-1007. https:/ / doi. org/10.1016/S0140-6736(15)60454-8

45. Yang X, Yu Y, Xu J, Shu H, Xia J, Liu H, et al. Clinical course and outcomes of critically ill patients with SARS-CoV-2 pneumonia in Wuhan, China: a single-centered, retrospective, observational study. Lancet Respir Med. 2020;8:475-81. https:/ / doi.org/10.1016/S2213-2600(20)30079-5

Address for correspondence: Roosecelis Brasil Martines, Centers for Disease Control and Prevention, 1600 Clifton Rd NE, Mailstop H18-SB, Atlanta, GA 30329-4027, USA; email: Roosecelis. BrasilMartines@cdc.hhs.gov 